\title{
Assisted-dying demand concentrated in four provinces
}

S ince medical assistance in dying (MAiD) became legal across Canada on June 17, most demand for the service is in four provinces. There have been at least 374 medically assisted deaths, according to The Globe and Mail, with 360 of those in British Columbia, Alberta, Ontario and Quebec. Nearly half were in Quebec, where MAiD has been legal for more than 10 months.

There have been 87 medically assisted deaths in Ontario, according to the Office of the Chief Coroner. The patient's average age was 71 . Twenty-one of the deaths occurred in Toronto, seven in Ottawa, seven in the York region, and fewer than five in other areas.

"Ontario's approach aims to support the provision of MAiD in a way that balances the rights of patients and health care providers, and which respects currently established laws and policies with respect to conscience rights of health care providers and facilities," David Jensen, media relations coordinator with the Ontario Ministry of Health and Long-Term Care, said in an email.

Alberta has seen higher-thanexpected demand, with two to four requests a week and no plateau in sight. There have been 29 assisted deaths this year; the patient's average age was 67. Most were in in Edmonton (14), followed by Calgary (7). Twenty-three requests were rejected for failing to meet eligibility criteria.

Alberta is considering increasing its resources to handle the demand, Dr. James Silvius, the lead for medical assistance in dying preparedness for Alberta Health Services, said in an email statement. "For physicians specifically, we recognize this can be emotionally demanding work, and therefore want to increase our numbers to spread the work out."

The province is providing information sessions for physicians so they know what supports are available if they

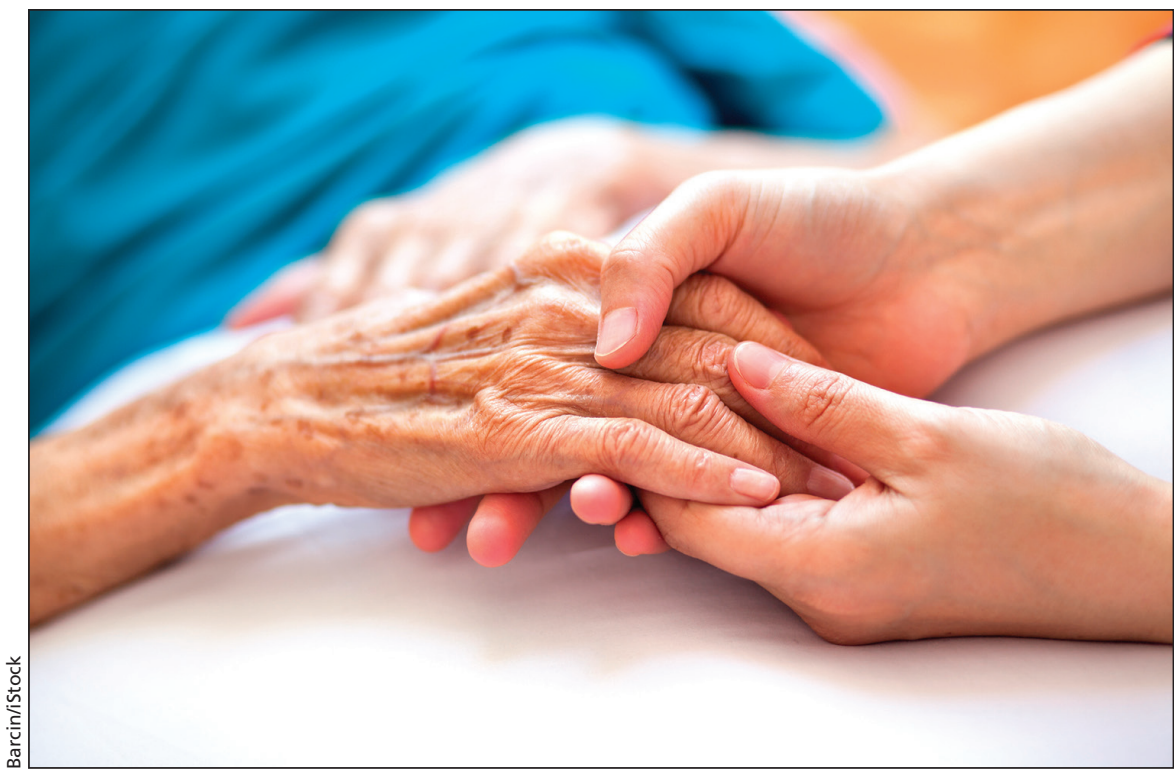

Some provinces have so few cases of assisted dying that reporting any details could breach patient confidentiality.

choose to participate. It is also developing formal educational resources and attempting to put in place a mentoring system for health care providers who may be unfamiliar with the drugs used in assisted dying.

In Manitoba, there have been around 60 requests for assisted dying, 14 of which were rejected for failing to meet the criteria. A dozen people have so far received the service. Most were from Winnipeg and around the age of 65 , though there have been outliers who were much older and younger. Two-thirds of those who died with medical assistance had cancer.

The Manitoba team in charge of assisted dying is based in Winnipeg and is comprised of three doctors, two nurses, two social workers, two pharmacists and one speech-language pathologist. They typically receive up to four calls a week for information or an assessment.

"The need and the demand were unknown when they first began their work and they continue to assess the needs of their clients against their capacity to ensure that they are able to keep up with demands of clients,"
Bronwyn Penner-Holigroski, a senior communication specialist for the Winnipeg Regional Health Authority, said in an email. The team is hiring a fulltime administrative support person and another part-time physician.

The number of assisted deaths reported to the Saskatchewan Ministry of Health has been low, fewer than five. The ministry is therefore not reporting additional information because those details could potentially lead to identification of the patients. Despite the low demand so far, the province has made the necessary preparations.

"Our goal is to ensure a balanced framework is in place for medical assistance in dying that provides appropriate safeguards for vulnerable individuals, while respecting the wishes and personal convictions of patients, families, and health care providers," Michelle Schmalenberg, director of health system policy and innovation for the Saskatchewan Ministry of Health, said in an email. "The Ministry of Health worked closely with regional health authorities and health professional regulatory bodies in developing standard processes and procedures for 
medical assistance in dying that are consistent with the new federal law."

Like Saskatchewan, New Brunswick has had few assisted deaths and is not releasing information about them at this time, not even the number of cases. That number might be made public later, Veronique Taylor, director of communications for the province's health ministry, said in an email.

Same goes for Nova Scotia. "In a province our size, releasing this information at this point in the evolution could serve to infringe patient confiden- tiality," read a statement from the Nova Scotia Health Authority forwarded to CMAJ by Kristen Lipscombe, a senior media relations advisor for the health authority. — Roger Collier, CMAJ

CMAJ 2016. DOI:10.1503/cmaj.109-5345 